Estudios sobre armas antiguas, arte militar $\mathrm{y}$ vida cultural en oriente y occidente XL (2020), pp. 73-92 ISSN: 0436-029X; eISSN: 1988-4168 https://doi.org/10.3989/gladius.2020.03

\title{
¿HACIA LA UNIDAD DE HISPANIA? EXPLICACIONES SOCIALES A LAS OFENSIVAS MILITARES VISIGODAS EN LA PENÍNSULA IBÉRICA (SIGLOS VI-VIII)*
}

\author{
TOWARDS HISPANIA'S UNITY? SOCIAL EXPLANATIONS TO \\ THE VISIGOTHIC MILITARY OFFENSIVES IN \\ THE IBERIAN PENINSULA (6TH-8TH CENTURIES)
}

POR

Pablo Poveda Arias ${ }^{* *}$

\section{RESUMEN - ABstract}

La guerra y la conquista fueron dos elementos claramente presentes en el proceso de construcción del reino visigodo hispano. El presente trabajo pretende ofrecer explicaciones alternativas al expansionismo territorial de los visigodos en Hispania por la vía armada, considerando las campañas ofensivas visigodas no como la consecuencia última de un proyecto secular dirigido a la consecución de la unidad peninsular bajo soberanía goda, sino de motivaciones mucho más inmediatas, que distaban del maximalismo. En este sentido, y sirviéndonos de los postulados de la historia social y de la antropología consagrada al estudio de la guerra, pondremos de relieve el papel de las motivaciones personales de los monarcas, en concreto su búsqueda de supervivencia política, y de las colectivas de la comitiva armada, en especial sus ansias de botín, como móviles principales de la actividad militar ofensiva visigoda.

War and conquest had a great incidence in the making process of the Visigothic kingdom in Hispania. In this paper, alternative explanations are proposed to the Visigoths' territorial expansionism by armed means, for which their offensive campaigns are analysed not as a consequence of a secular project aimed at achieving the peninsular unity under Gothic sovereignty, but as a result of immediate motivations which were far from maximalism. In this regard, we will emphasize the role of the monarch's personal motivations, in particular the pursuit of their political survival, and the army's collective incentives, such as their eagerness for plunder, as the main driving force of Visigothic offensive military activity. For this purpose, the assumptions derived from social history and the anthropology devoted to the study of war will become very useful analysis tools.

\section{Palabras Clave - Keywords}

Botín de guerra; conquista; ejército visigodo; Hispania; historia social; monarquía visigoda.

Plunder; Conquest; Visigothic Army; Hispania; Social History; Visigothic Monarchy.

\section{CÓMO CITAR ESTE ARTículo / CitATion}

Poveda Arias, P. (2020): «¿Hacia la unidad de Hispania? Explicaciones sociales a las ofensivas militares visigodas en la península ibérica (siglos VI-VIII)». Gladius, 40: 73-92. https://doi.org/10.3989/gladius.2020.03

* El presente estudio ha sido desarrollado en el marco de un proyecto de investigación postdoctoral financiado por la Fritz Thyssen Stiftung (Ref. 49.19.0.014GE) y del proyecto de investigación HAR2016-76094, financiado por el Ministerio de Ciencia e Innovación.

** Universität Hamburg. RomanIslam - Center for Comparative Empire and Transcultural Studies, pablo.poveda. arias@uni-hamburg.de / ORCID iD: http://orcid.org/0000-0002-2691-7912 


\section{INTRODUCCIÓN}

Es incuestionable que la guerra y la conquista armada fueron dos de los principales determinantes en el proceso de construcción del reino visigodo en su fase hispana. No en vano los textos inciden en ambas como fuentes de legitimación de la dominación visigoda en el espacio peninsular ${ }^{1}$; un dominio que por otro lado se logró después de un proceso largo y lento, que se extendió desde principios del siglo VI hasta la conquista del último enclave imperial en la Península en la tercera década del siglo VII. Un factor que influyó indudablemente en ello fue la fragmentación política y social del escenario ibérico durante los siglos $\mathrm{V}_{\text {y }} \mathrm{VI}^{2}$, además del punto de partida, dado que en el momento de la derrota visigoda en Vouillé el control visigodo sobre Hispania era aún bastante limitado ${ }^{3}$. Sin embargo, consideramos que hubo otros elementos que condicionaron esta lentitud en el proceso, en concreto los objetivos que motivaron, no solo el expansionismo visigodo, sino en general el resto de las campañas militares ofensivas de los godos en la península ibérica. Nuestra pretensión a lo largo de las siguientes páginas será ahondar en los móviles que llevaron a los visigodos a organizar las distintas expediciones ofensivas, concluyesen estas en conquista o no, para lo cual ofreceremos explicaciones alternativas a las tradicionalmente planteadas. El marco cronológico propuesto abarca desde el año 507, año de la citada batalla de Vouillé, hasta la propia caída del reino visigodo en el 711, aunque la naturaleza lacónica de algunos períodos hará que recurramos de forma más frecuente a aquellos reinados, como el de Leovigildo o el de Wamba, para los cuales contamos con una mayor masa documental. El objetivo final es entender en mayor medida las dinámicas militares del reino visigodo y su imbricación con aquellas de orden social. Con este fin, enmarcamos este estudio en el ámbito de la historia social, cuyas últimas aportaciones han contribuido a avanzar en el estudio del elemento militar durante la Antigüedad tardía y la Alta Edad Media. De forma complementaria, la teoría antropológica aplicada al estudio de la guerra se tornará un instrumento de enorme utilidad al ofrecer una visión original del comportamiento humano ${ }^{4}$.

Como punto de partida, rechazamos la idea profundamente arraigada en la historiografía de considerar la conquista militar visigoda sobre Hispania como un fin en sí mismo dirigido a lograr en última instancia la unidad del espacio ibérico bajo soberanía goda ${ }^{5}$. A nuestro parecer, tales planteamientos derivan de una extrapolación de la ideología construida por autores

1 Por ejemplo, Isid. Hisp., Hist. De laude Spaniae, 26-30; 67; 69; Etym. XVIII, 2, 1. Véase Cazier, 1994: 298. Este valor legitimador del expansionismo visigodo por la vía armada tiene su reflejo también en la etapa tolosana. Sid. Apoll., Epist. VII, 7, 2. Véase al respecto, Diesner, 1978: 131-132; Reydellet, 1981: 522-523; Wolf, 1999: 16-17; Valverde Castro, 2000: 154-156; Teillet, 2011: 493; Rus Rufino, 2015: 87.

2 Ponen de relieve este fenómeno como uno de los rasgos definidores del período post-imperial: Valverde Castro, 2000: 127-141; Wickham, 2009: 163; Wood, 2012: 38-40. Véase también Fernández, 2017.

3 En estos momentos el dominio visigodo sobre Hispania se limitaría al control de la Tarraconense y quizás de Mérida, aunque con el tiempo la ascendencia sobre esta última se acabaría perdiendo. Véase Kulikowski, 2004: 203-205; Arce, 2009: 35; Wickham, 2009: 88. Es así como entendemos el testimonio de Isidoro de Sevilla cuando afirma que el regnum visigodo previo a Leovigildo se restringía a unos límites muy estrechos. Isid. Hisp., Hist. 49. No debemos, por tanto, dejarnos engañar por los relatos de Juan de Bíclaro e Isidoro cuando, al hacer un balance de los logros militares de Leovigildo, etiquetan la toma de territorios como una «reconquista» $\mathrm{y}$, por extensión, califican a sus enemigos como meros rebeldes. Ioh. Bicl., Chron. 10, 52-54; Isid. Hisp., Chron. 403. En la línea marcada por Díaz, 2004: 51, cabe la posibilidad de que tales argumentos hubiesen hecho referencia a los tiempos en los que los visigodos actuaban en Hispania como garantes de los intereses romanos. En definitiva, los triunfos militares visigodos del siglo VI referidos en las fuentes deben ser entendidos ante todo como conquistas ex novo y, por tanto, como un proceso de imposición del poder godo sobre poblaciones que hasta ese momento habían escapado a su control. Kulikowski, 2005: 48.

4 El valor principal de esta radica en su no mediatización por los prejuicios que los historiadores solemos aplicar a partir de nuestra inmersión en el debate historiográfico más especializado.

5 Defendiendo este objetivo maximalista, Reinhart 1944-1945: 98-99; Gibert, 1956; Reydellet, 1981: 521; Sayas Abengochea, 1988; Rus Rufino, 2015: 86-87, entre otros. 
como Isidoro de Sevilla, quien imprimió al proceso expansionista de unos claros prejuicios teleológicos, que ante todo obedecían a los intereses políticos del tiempo en el que vivió, pero que distaban sustancialmente de la realidad pretérita que describía. Tales intereses quedan patentes, por ejemplo, en su defensa de un proyecto secular dirigido a la consecución de la unidad de Hispania por parte del pueblo godo; una idea que debemos enmarcar en el contexto de conquista de las posesiones imperiales en la Península, la cual consideramos que estaría intentando justificar. De esta manera, la historia funcionó para Isidoro como un instrumento destinado a influir en su presente con el fin de favorecer la unidad y la cohesión de la población hispana en torno a sus gobernantes ${ }^{6}$. Desde este punto de vista, sus escritos históricos habrían únicamente extrapolado al pasado los logros políticos de su presente.

En este sentido, es posible que los reyes que precedieron a Suintila, a quien se atribuye la unificación peninsular bajo dominio visigodo, no hubiesen perseguido de forma consciente unificar Hispania bajo su soberanía y que, por tanto, sus campañas militares hubiesen obedecido a otro tipo de motivaciones. En caso contrario no se entiende, por ejemplo, la despreocupación de Recaredo a la hora de emprender campañas militares de carácter ofensivo, un fenómeno que llama aún más la atención si atendemos al hecho de que se trató de uno de los monarcas más poderosos ${ }^{7}$. Atendiendo a tales credenciales, lo lógico habría sido que hubiese aprovechado la estabilidad interna para lanzarse a conquistar los enclaves peninsulares en manos del Imperio. Sin embargo, lejos de mostrar la hiperactividad expansiva de su padre Leovigildo, su actitud militar distó mucho de perseguir la anexión de nuevos territorios. Es cierto que disponemos de evidencias que remiten a conflictos entre romano-imperiales y visigodos durante su reinado, pero tal y como pone de manifiesto Isidoro de Sevilla, tales enfrentamientos fueron consecuencia de los abusos imperiales (romana insolentia), esto es, de incursiones bizantinas en territorio visigodo y, por tanto, no de una acción de conquista por parte de Recaredo. De hecho, sabemos que el conflicto se saldó en derrota visigoda y en la consiguiente pérdida de plazas fuertes ${ }^{8}$. Advertimos por tanto una actitud eminentemente defensiva frente al enemigo imperial, más caracterizada por la búsqueda, no tanto de confrontación, sino de una coexistencia con él ${ }^{9}$. Podríamos decir que, en general, la política militar de Recaredo se limitó a asegurar posiciones y a defender los territorios bajo su dominio ${ }^{10}$. En consecuencia, la persecución de la unidad hispana no supuso, no ya una prioridad, sino ni siquiera una parte integrante de su programa político. Esta misma actitud se percibe durante los últimos años de reinado de Sisebuto, quien llegó a tener en su mano, en caso de haberlo deseado, acabar con la dominación imperial en la Península ${ }^{11}$.

6 Sobre el proyecto ideológico isidoriano, Wood, 2012. Tal y como afirma este autor: «he tried to understand, explain and, most importantly, to influence the context in which he found himself through historical composition» (Ibidem: 2).

7 Véase Castellanos, 2007.

8 Isid. Hisp., Hist. 54. Sobre este fragmento, véase Velázquez, 2000: 591-592; Vallejo Girvés, 2012: 269-277.

9 De hecho, se advierte en este reinado una priorización por parte de la corte visigoda de la diplomacia como vía de solución de conflictos, especialmente en lo que al Imperio se refiere. Vallejo Girvés, 1996: 209. En algunos casos, el propio monarca incluso recurrió a la mediación del papa Gregorio Magno con el fin de solucionar las disputas con Constantinopla sin necesidad de llegar a las armas. Greg. Magn., Reg. Epist. IX, 229.

10 Isid. Hisp., Hist. 55. Velázquez, 2000: 592; Díaz, 2010: 360; Thompson, 2011: 34.

11 Vallejo Girvés, 2012: 334-368 presenta un balance pormenorizado de la relación de fuerzas y del estado de la situación al final del reinado de Sisebuto y a principios del de Suintila. Es cierto que estos dos monarcas sí se decidieron por la conquista, en el caso de Sisebuto únicamente durante una parte de su reinado, pero tal y como veremos más adelante, sus objetivos podían distar bastante del maximalismo. Asimismo, es cierto que los predecesores de este último, Witerico y Gundemaro, sí organizaron campañas ofensivas contra el Imperio (véase infra), pero tales acciones se llevaron a cabo de forma esporádica y adoptaron un perfil bajo (Wood, 2010: 309), lo que tampoco apunta a un fuerte interés por lograr la unidad hispana. 
Otro argumento que nos permite negar la búsqueda consciente de la unidad hispana es la estrategia militar seguida. Los distintos monarcas visigodos, en lugar de centrar todos los esfuerzos militares de las expediciones ofensivas en un mismo lugar hasta la toma del mismo, solían alternar los objetivos, lo que apunta a un desinterés por la conquista final de los territorios objeto de sus ataques. Quizás el caso más elocuente al respecto es el de Leovigildo, quien aparte de alternar sus objetivos militare ${ }^{12}$, lo encontramos al comienzo de su reinado atacando el territorio malacitano y bastetano antes de controlar el enclave y el territorium de Córdoba ${ }^{13}$, hecho que no se adecúa a una lógica militar destinada en última instancia a la conquista del conjunto del territorio hispano.

\section{INSTRUMENTALIZACIÓN REGIA DE LA GUERRA OFENSIVA}

Habiendo dejado en claro que los visigodos no se vieron abocados sin mayor explicación a un proceso de conquista del conjunto de Hispania, cabe preguntarse por los objetivos perseguidos cuando emprendieron acciones ofensivas en la Península. En aras de responder esta pregunta, consideramos que las distintas campañas obedecieron a unos intereses que distaban mucho del maximalismo ${ }^{14}$. En su lugar, planteamos la hipótesis de que el proceso de expansión militar de los visigodos en Hispania y, en general, sus iniciativas militares ofensivas obedecieron a motivaciones mucho más inmediatas. Dentro de esta perspectiva, la consecución de la unidad hispana pudo actuar únicamente como una justificación y un recurso literario esgrimido a posteriori. Ahora bien, ¿cuáles eran esos intereses? En este punto debemos hacer una diferenciación entre las motivaciones personales del monarca de turno, por un lado, y los móviles colectivos que lanzaban a la comitiva armada a seguir a su rex a la batalla ${ }^{15}$. En lo que se refiere a la monarquía, nos inclinamos más a pensar que en la mayoría de las ocasiones los reyes priorizaron sus propios intereses ${ }^{16}$, sin que estos entrasen necesariamente en contradicción con los de su comitiva armada. De hecho, en algunos casos los objetivos de unos y otros podían coincidir. Es más, la habilidad de un líder se reflejaba también en su capacidad de imbricar con éxito los intereses personales y los del grupo a su cargo y, por tanto, sin que la consecución de los primeros supusiera un menoscabo de los colectivos. En este sentido, un rey determinado podía promover conflictos con enemigos exteriores para dar satisfacción a unos anhelos personales que poco o nada tenían que ver con los que pretendía su comitiva armada con tales enfrentamientos ${ }^{17}$. Sin embargo, los intereses de ambos podían converger en una misma vía, en este caso la guerra.

Pero ¿qué intereses personales podían subyacer con la promoción de campañas militares por parte de la monarquía visigoda? Desde los tiempos tolosanos los reyes visigodos se vieron inmersos en un ambiente de competencia política constante por acceder al trono, primero, y por mantenerlo, después. La derrota de Vouillé, con la consiguiente fragmentación de lealtades políticas, únicamente perpetuó esta situación, tal y como revelan las numerosas referencias a

\footnotetext{
12 A lo largo de las siguientes páginas presentaremos una relación detallada de sus campañas. Véase también García Moreno, 2008.

13 Ioh. Bicl., Chron. 12.

14 Una postura similar, aunque aplicada únicamente al caso de Leovigildo, en Fernández Delgado et alii, 2013: 163.

15 Planteando esta distinción desde la antropología, Ferguson, 2008: 37-38, 44-46; Otterbein, 2009: 34. Véase también Giddens, 1984.

16 Los intereses personales no dejan de constituir un factor más a tener en cuenta en la acción política y social. Moore, 2011: 10 .

17 Desde la antropología se ha reivindicado esta relación entre intereses colectivos y personales. Es el caso de Sahlins, 1963: 289.
} 
asesinatos y usurpaciones a lo largo de todo el período ${ }^{18}$. Incluso Leovigildo, a pesar de la imagen de fortaleza que se le suele imprimir a su reinado, tuvo que hacer frente hasta prácticamente el final de sus días a movimientos de oposición promovidos desde determinados sectores aristocráticos que le impidieron disfrutar de un mínimo de estabilidad en su regia posición ${ }^{19}$. Dentro de este contexto, y en un horizonte político dominado por unas aristocracias de naturaleza castrense, la exhibición de unas sobresalientes capacidades militares se tornaba una manera bastante eficaz de reivindicarse en ese escenario de competencia interna, adquiriendo la guerra un valor propio como legitimadora del poder regio ${ }^{20}$. Es así como se entiende que la monarquía visigoda mantuviese a lo largo de toda su historia su naturaleza guerrera, reflejada en la condición del rey como líder supremo del ejército ${ }^{21}$. Por esta misma razón los reyes visigodos se vieron forzados a lo largo de toda su historia a emprender campañas ofensivas de carácter regular. Tales expediciones, en caso de saldarse en victoria, infundirían a los monarcas de un prestigio emanado de su capacidad militar, el cual les permitiría sobresalir por encima de sus competidores ${ }^{22}$. Por otro lado, la guerra podía convertirse en una manera eficaz de desviar la atención de la aristocracia de la lucha faccional hacia objetivos comunes, con independencia de que difiriesen los intereses subyacentes a tales expediciones. A esto se le suma su capacidad de cohesionar al grupo visigodo en torno al líder ${ }^{23}$. A la luz de tales beneficios, consideramos que algunos monarcas visigodos instrumentalizaron conscientemente el conflicto militar, concretamente el de carácter ofensivo, en su favor personal, con el objetivo final de perpetuarse en el poder ${ }^{24}$. Es más, podemos plantear la hipótesis de que estas iniciativas se planearon en primera instancia para dar satisfacción a tales intereses de eminente naturaleza personal, esto es, concibiéndolas como una vía de supervivencia política del monarca frente a las tendencias competitivas que amenazaban de manera constante su posición y su persona ${ }^{25}$. De hecho, esta instrumentalización política de la guerra puede ser interpretada como una de las claves que explica el éxito que tuvieron algunos de los monarcas a la hora de mantenerse en el trono ${ }^{26}$. En este esquema, y respecto a las motivaciones regias aducidas, las justificaciones concretas y los intereses colectivos habrían desempeñado un papel secundario e instrumental ${ }^{27}$.

El monarca que posiblemente mejor percibió los beneficios que podía reportarle la guerra en aras de consolidarse en el trono e imponerse sobre sus competidores fue Leovigildo, pa-

18 Ilustrando tales dinámicas, Greg. Tur., DLH, III, 30; Fredeg., Chron. III, 42; IV, 82. Véase Besga Marroquín, 2007.

19 Hay pruebas contundentes que apuntan hacia esta dirección. Una de las evidencias más elocuentes es la referencia a ejecuciones, destierros y confiscaciones a determinados grupos aristocráticos. Isid. Hisp., Hist. 51. Otro testimonio se refiere a intentos de usurpación que, aunque no se recogen con detalle, se encuentran implícitamente aludidos. Ioh. Bicl., Chron. 50. Finalmente, cabe mencionar en los últimos años de su reinado la rebelión de su hijo Hermenegildo, y que sumió a los visigodos en un contexto de guerra civil. Ioh. Bicl., Chron. 54. La existencia de dichos sectores opositores queda reflejada también en la crónica del biclarense cuando hace mención a la restitución de bienes por parte de Recaredo a aquellos que habían sufrido las confiscaciones regias previas a su reinado. Ioh. Bicl., Chron. 86.

20 Sobre la incidencia del factor militar en la legitimación de los monarcas visigodos, véase Poveda Arias (e. p.). Remarca el papel de la competencia como motor de la acción social: Theuws, 1990: 43.

21 King, 1981: 91; Valverde Castro, 2000: 233.

22 Véase Sahlins, 1963: 289.

23 Poniendo de relieve este valor cohesionador de la guerra, Smith, 1981; Descola, 1996; Bossen, 2006b. Recientemente, en lo que al caso visigodo se refiere, ha puesto de relieve este valor de la guerra para etapas anteriores a las aquí tratadas, Ruchesi, 2016.

24 De nuevo la antropología se torna un recurso de enorme utilidad a la hora de estudiar esta instrumentalización de la guerra por parte de los líderes. Sahlins, 1963: 254-255; Bossen, 2006a: 254-255; Ferguson, 2008: 44-46.

25 Wood, 2006: 61 ha planteado también esta búsqueda de supervivencia política como motivación principal de la acción regia.

26 Sustentando tales postulados desde la antropología, Bossen, 2006a: 254-255.

27 Véase Ferguson, 2008: 44. 
radigma de rey guerrero visigodo victorioso ${ }^{28}$. El propio Isidoro de Sevilla pone en relación la actividad militar de este monarca con la necesidad de evitar los peligros inherentes a la ociosidad regia, entre ellos las propias amenazas internas ${ }^{29}$, lo que supone una confirmación bastante elocuente de la instrumentalización de la guerra en pro de los intereses regios ${ }^{30}$. De esta manera, Leovigildo lanzó desde comienzos de su reinado campañas regulares de carácter ofensivo, prácticamente de frecuencia anual, siendo el monarca para el cual contamos con la mayor relación de acciones de este tipo ${ }^{31}$. Esta instrumentalización de la guerra como vía de consolidación del poder regio es especialmente perceptible al comienzo de muchos de los reinados. En el caso de los monarcas de la primera etapa, esta actitud se observa en los casos de Agila, Atanagildo y, especialmente, Leovigildo, aunque no es descartable para la mayoría de los reinados ${ }^{32}$. En lo que se refiere a momentos posteriores, interpretamos en este sentido las campañas de Witerico, Gundemaro, Suintila, Chindasvinto, Wamba, Egica y Rodrigo ${ }^{33}$. Para algunos de estos reinados tenemos además la certeza de que tales campañas coincidieron con contextos de abierta competencia entre el monarca y otros personajes potencialmente capaces de disputarle el trono ${ }^{34}$. Sin embargo, aunque es cierto que se aprecia una mayor hiperactividad militar en los primeros años de muchos de los reinados, las acciones ofensivas no dejaron de producirse en momentos más avanzados, con más o menos regularidad, especialmente en el norte peninsular. Es cierto que las fuentes únicamente recogen alusiones aisladas e indirectas a estas, sin embargo, ello puede ser interpretado como un indicio de la normalización de este tipo de acciones $^{35}$.

\section{Motivaciones COLECTIVAS DE LA ACTIVIDAD MILITAR OFENSIVA VISIGODA Y SU INCIDENCIA EN LA CONQUISTA DEL TERRITORIO}

Hemos dejado en claro los intereses regios que subyacían a la actividad militar ofensiva. Sin embargo, el mero deseo regio no explica la capacidad que tenía la guerra para cohesionar

\footnotetext{
28 Sobre su reinado, véase García Moreno, 2008.

29 Isid. Hisp., Hist. 49.

30 En relación a este monarca y su actividad militar, véase también Heather, 1998: 279; Martin, 2003: 313; Frighetto,
} 2018: 166-168.

31 Es posible que la excepcionalidad de Leovigildo venga dada por la naturaleza de nuestras principales fuentes, que aportan muchos más datos sobre este reinado y el de su hijo Recaredo que para el resto, por lo que no podemos descartar que otros monarcas hubiesen actuado de manera similar.

32 Para el reinado de Agila: Isid. Hisp., Hist. 45. Para el caso de Atanagildo, sirva como ejemplo Greg. Tur., $D L H$ IV, 8. Aquí también deberíamos destacar el caso de Teudis, aunque las noticias relativas a su reinado y, en particular, a su actividad militar son muy escasas, destacando su campaña en el enclave de Septem (Ceuta). Isid. Hisp., Hist. 42.

33 De las campañas de Witerico, se dice que culminaron en derrota para el visigodo. Isid. Hisp., Hist. 58. Gundemaro llevó a cabo dos campañas militares en dos años de reinado. Isid. Hisp., Hist. 59. Para el caso de Suintila, Isid. Hisp., Hist. 63. Sobre la expedición de Chindasvinto, Moreno Resano, 2011: 304, quien intuyó aquí una intencionalidad similar a la aquí defendida. Sobre la campaña de Wamba, Iul. Tol., Hist. Wamb. 9. Isla, 2010: 46; Parra Romo, 2018: 223. Para el caso de Egica, Iul. Tol., Progn. Fut. saec. lib. tres Praef., 80-82. Isla, 2010: 66-67. Para el caso de Rodrigo, véase ibidem: 117. Es posible que Chintila se hubiese visto obligado también a emprender campañas similares, también durante sus primeros años de reinado, las cuales se intuyen en Braul. Caesar., Confess. uel profess. fid. Iudeor. ciuit. Tol. 104-107. Quizás el canon 3 del Concilio de Mérida, celebrado en tiempos de Recesvinto, se esté refiriendo en parte a este tipo de ofensivas visigodas cuando alude a la partida del rey y el ejército a la batalla. Conc. Emer. (a. 666) c. 3.

34 Pongamos como ejemplo el caso de Wamba, a quien la revuelta de Paulo le sorprendió en su campaña ofensiva contra los vascones. Iul. Tol., Hist. Wamb.

35 Se inclinan por esta idea: Novo Guisán, 1992: 71; Halsall, 2003: 63; Petersen, 2013: 164. Tengamos en cuenta que en muchas ocasiones la difusión escrita de tales campañas obedeció a intereses ideológicos como era el persuadir a los sectores aristocráticos opositores de no organizar conjuras contra el monarca reinante. La Historia Wambae quizás resulte el caso más paradigmático al respecto. Ruchesi, 2018-2019: 73. Véase también Martínez Pizarro, 2005. 
al grupo armado visigodo y seguir a su rey a la batalla. Para ello, era necesario persuadir a las tropas de que el conflicto podía resultarles beneficioso, más allá de las motivaciones personales del monarca. La motivación colectiva no era una cuestión baladí, sino que era fundamental para lograr una convocatoria efectiva del grupo armado en las campañas de naturaleza ofensiva. Ello se debe a que la participación en este tipo de expediciones era voluntaria. No debemos por tanto confundir las campañas ofensivas con aquellas destinadas a la defensa del reino ${ }^{36}$, en las que sí era obligatoria una participación masiva de los hombres libres del reino y, en especial de la aristocracia guerrera del reino ${ }^{37}$. Este factor de voluntariedad no fue sin embargo respondido con pasividad por parte de las tropas. Al contrario, la ausencia de medidas legales dirigidas a fomentar la participación en las expediciones ofensivas apunta a una satisfactoria movilización del ejército. Es cierto que tampoco se requería una ingente masa militar, sino que, tal y como aplica R. Van Dam para el caso merovingio, la guerra se habría llevado a cabo por grupos pequeños, siendo muy excepcionales los enfrentamientos de gran envergadura ${ }^{38}$.

La propia idea de voluntariedad es matizable, siendo fundamentalmente aplicable a la aristocracia militar del reino. Ello se debe a la propia naturaleza del ejército visigodo ${ }^{39}$, conformado desde momentos bastante tempranos por la suma de las comitivas armadas privadas de la aristocracia militar del reino. Como resultado, las fuerzas militares visigodas constituían un cuerpo heterogéneo y, en consecuencia, profesionalizado en grado desigual ${ }^{40}$. La incidencia central de los ejércitos privados queda patente desde el siglo $\mathrm{VI}^{41}$, tal y como revela Teudis y su preocupación, desde antes incluso de acceder al trono, por aglutinar en torno a su persona y bajo su directa dependencia un poderoso cuerpo militar. No rechazamos incluso que esta necesidad hubiese motivado en última instancia su matrimonio con una rica aristócrata hispanorromana ${ }^{42}$. Por otro lado, no hay nada que induzca a pensar en la pervivencia de un ejército visigodo asalariado durante el siglo $\mathrm{VI}^{43}$, especialmente atendiendo al hecho de que, desde antes incluso de la caída del Imperio, los ejércitos privados y los factores personales empezaron a determinar las dinámicas militares en Occidente ${ }^{44}$. Sí podemos aceptar la existencia de un cuerpo militar permanente ${ }^{45}$, pero únicamente aquel radicado en las plazas fuertes situadas en puntos estratégicos fundamentales para la defensa del reino. Sin embargo, creemos que tam-

\footnotetext{
36 Presentando una distinción más o menos similar, Isla, 2010: 47-49.

37 Es a estas últimas a las que se estarían refiriendo las leyes militares de Wamba, Ervigio y Egica. $L V$, V, 7, 19; IX, 2, 8-9. Sobre estas, véase Isla, 2010; Díaz, 2012: 190-201.

38 Van Dam, 2005: 211. Véase también Reuter, 1997.

39 La composición del ejército visigodo se encontraba íntimamente ligada a las dinámicas sociales del momento. Véase Pérez Sánchez, 1989. Esta relación entre el elemento militar y la sociedad en el Occidente post-romano articuló el trabajo de Halsall, 2003. Por otro lado, debemos asumir para los momentos tratados una composición mixta del ejército visigodo, es decir, con elementos godos y romanos. Isla, 2010: 18-20. Sobre la organización del ejército visigodo, véase también Sánchez-Albornoz, 1970. Para cuestiones de intendencia y estrategia militar, véase Parra Romo, 2018.

40 Sánchez-Albornoz, 1970: 35-38; Barbero y Vigil, 1978: 44-52; Isla, 2010: 87; Díaz, 2012: 189. Una confirmación de estas dinámicas la encontramos en el epígrafe de Opilano. Moreno Resano, 2011: 305.

41 Isla, 2010: 67-88, donde se analiza el funcionamiento de los ejércitos privados durante los siglos VI y VII. Centrándose por su parte en el siglo VI, Petersen, 2013: 58-69.

42 Procop., $B G \mathrm{~V}, 12$. Isla, 2010: 75.

43 Algunos sectores de la historiografía han defendido la coexistencia entre estas y un ejército regular y profesional de carácter público para la sexta centuria, considerando la imposición de las dinámicas privadas sobre las públicas únicamente a partir del siglo VII. Pérez Sánchez, 1989: 117. Sin embargo, tales ideas dan por sentado la vigencia de un férreo principio de gobierno público durante el siglo VI y que, únicamente en virtud de él y dando continuidad a las dinámicas tardorromanas, existía un cuerpo armado sobre el que el monarca decidía y disponía. Otros, por el contrario, defienden el proceso contrario al atribuir la creación de un ejército profesional y permanente a partir de los reinados de Leovigildo y Recaredo. Osborne, 2018-2019.

44 Lécrivain, 1890: 271-272. Para el caso hispano, véase Sanz, 1986.

45 Sánchez-Albornoz, 1970: 13-15; Pérez Sánchez, 1989: 117.
} 
poco se trataban de tropas asalariadas, sino que las dinámicas privadas pudieron reproducirse también en este caso, con un cargo militar que se hacía cargo de la defensa del lugar con sus hombres y a partir de las tierras que el rey le entregaba a cambio de su servicio ${ }^{46}$. Es en esta tipología en la que enmarcamos la entrega regia de tierras en la región del Bierzo al cuñado de Fructuoso so pretexto de emplearlas para sufragar los gastos generados por las -aquí denominadas - expediciones públicas, las cuales consideramos en este caso acciones defensivas dirigidas a hacer frente a posibles incursiones de los pueblos del norte ${ }^{47}$.

De esta manera, el ejército que participaba en las expediciones ofensivas del monarca estaría conformado principalmente por la mesnada real, es decir, sus dependientes directos, y por los integrantes de las comitivas privadas de la aristocracia militar del reino que acudía a la llamada del rey ${ }^{48}$. Era por tanto esta aristocracia guerrera la que tenía la libertad de elegir si participaba en las expediciones, no así los integrantes de su grupo armado, cuyos vínculos de dependencia con su señor les habrían privado de cierta capacidad de decisión ${ }^{49}$. En consecuencia, los reyes únicamente podían conseguir la participación activa de los potentes si estos veían un interés y un beneficio en la actividad militar. Como apuntamos anteriormente, las motivaciones colectivas con la guerra ofensiva, en este caso de la aristocracia, muchas veces tenían poco que ver con las de los reyes que impulsaban las distintas expediciones. Entonces, ¿qué lanzaba al grupo militar a seguir a su rex a la batalla? Aquí debemos valorar la incidencia de dos factores, por un lado, el fomento de una idea de alteridad y, por otro, el deseo de obtención de un sustancioso botín de guerra.

La elección de un agente de alteridad era fundamental para lograr desviar la atención de la competencia interna y lanzar a la aristocracia a la batalla. A fin de cuentas, la exacerbación de las identidades antagónicas tenía la capacidad de minimizar las diferencias internas en el seno de un grupo ${ }^{50}$, al mismo tiempo que hacían más atractivas las ofensivas militares. En este punto, los monarcas habrían presentado las campañas en clave de venganza por ataques previos del enemigo ${ }^{51}$; aunque la propia idea de alteridad habría sido una justificación suficiente para emprender iniciativas militares contra un objetivo externo. A la hora de seleccionar tales enemigos, el espacio peninsular ofrecía una amplia nómina de grupos y pueblos ajenos a los visigodos, y por tanto proclives de servir a tal efecto. Entre estos, el actor imperial, que estuvo presente en el escenario hispano desde mediados del siglo $\mathrm{V}$ hasta su expulsión en el primer tercio del siglo VII ${ }^{52}$, constituyó un agente de alteridad consolidado en el imaginario colectivo como enemigo histórico de los godos ${ }^{53}$. No en vano Leovigildo lo escogió como el primero

46 Es posible que Isidoro se estuviera refiriendo a estas cuando alude al pago de un stipendium por servicios militares. Isid. Hisp., Etym. V, 7, 1.

47 Vit. Fruct. 3, 6-11. Otra lectura en Sánchez-Albornoz, 1970: 39-41.

48 En una línea más o menos similar, Reuter, 1997. Esta distinción se aplicó en su día para el contexto bajoimperial. Lécrivain, 1890: 267. Observamos un reconocimiento legal temprano de las comitivas armadas privadas en $C E$, 310. Testimoniando la existencia de estos séquitos privados en época tolosana, Sid. Apoll., Epist. I, 2, 9. Véase Heather, 1998: 200. En momentos más tardíos, a estas convocatorias habrían acudido ante todo los componentes palatinos de la aristocracia visigoda junto a sus comitivas privadas. Isla, 2010: 47-49. Una confirmación a esta composición la encontramos en Iul. Tol., Hist. Wamb. 9, 168-170. En un plano general, profundiza en los mecanismos de reclutamiento militar en el mundo post-imperial, Halsall, 2003: 40-70.

49 Consideramos que la ley que regula los castigos impuestos sobre aquellos que intentaban liberarse del reclutamiento militar se estaría refiriendo a estos efectivos. $L V$, IX, 2, 5.

50 Smith, 1981: 391.

51 Remarca la venganza como móvil militar, Otterbein, 2009: 4, 36. Es posible que fuera a consecuencia de este tipo de acciones previas por las que los visigodos catalogaron a los cantabri como peruasores, en el sentido de «invasores». Ioh. Bicl., Chron. 32. Véase Diego Santos, 1979: 25; Sayas Abengochea, 1988: 196; Díaz, 2006: 48. Así se justifica la campaña de Suintila contra los vascones. Isid. Hisp., Hist. 63. Presentamos más evidencias al respecto infra.

52 Sobre la dominación imperial en Hispania, Vizcaíno Sánchez, 2009; Vallejo Girvés, 2012.

53 Para un reflejo en las fuentes de esta idea, véase Hillgarth, 1970: 275-277. 
de sus objetivos militares ${ }^{54}$. Junto a los romanos orientales, había otros pueblos contra los cuales los visigodos dirigieron sus esfuerzos militares. A fin de cuentas, no convenía presionar en exceso al Imperio para evitar una contundente respuesta de Constantinopla, más cuando había otros grupos que podían desempeñar la misma función. Entre estos, el más perceptible en la memoria colectiva visigoda era el de los vascones, un pueblo que, aunque las fuentes lo engloban bajo un mismo etnónimo, en ningún momento actuó de forma cohesionada o poseyó una conciencia clara de sus particularidades ${ }^{55}$. Por extensión su territorio habría carecido de una delimitación y de una articulación interna bien definidas ${ }^{56}$. Sin embargo, el empleo de una única etiqueta, adoptada por los autores a partir de referentes antiguos que poco o nada tenían que ver con las sociedades descritas ${ }^{57}$, reforzaba la percepción de alteridad. Una situación similar se habría reproducido en el caso de los sappos de la Sabaria, de cuya existencia tenemos únicamente constancia a partir de una campaña de Leovigildo ${ }^{58}$. En este caso consideramos que la propia idea de alteridad hacia este colectivo no fue más que un constructo literario, un recurso retórico, en este caso de Juan de Bíclaro, que adoptó un discurso étnico tomado de tiempos imperiales. Siguiendo tales presupuestos, cabe la posibilidad de que los sappos no hubiesen tenido nunca la sensación de pertenencia a una comunidad étnica diferenciada del resto de la población hispana. En este sentido, las etiquetas étnicas habrían sido únicamente un mero cultismo instrumentalizado para exacerbar una idea de alteridad respecto a los visigodos y, así, facilitar y legitimar acciones militares contra tales colectivos ${ }^{59}$. Es por esta razón por la cual estos etnónimos aparecen ante todo en contextos de tensión y conflicto con estos grupos ${ }^{60}$. La única certeza más o menos segura en torno a los sappos es que se trataban de comunidades que se habían desarrollado de forma independiente hasta el reinado de Leovigildo, no tanto por incapacidad para absorberlas, sino simplemente por indiferencia por parte del poder central visigodo $^{61}$. La misma situación le atribuimos a otros grupos que aparecen en estos contextos de conflicto con los visigodos, como es el caso de los rucones, asimilados a los luggones de época altoimperial, y los astures ${ }^{62}$.

Con todo, estimamos que el factor de alteridad desempeñó únicamente un papel relativo a la hora de lanzar a los visigodos a emprender expediciones militares ofensivas. En su lugar, creemos que el principal acicate era de orden material, como era el deseo de obtener un nutrido botín de guerra ${ }^{63}$. A fin de cuentas, desde tiempos tardorromanos ${ }^{64}$, el pillaje constituyó una

54 Ioh. Bicl., Chron. 12; 17; Isid. Hisp., Hist. 49.

55 Véase Sayas Abengochea, 1987: 64-67; Collins, 1984: 8.

56 De Brestian, 2011; Moreno Resano, 2015: 354-356.

57 De Brestian, 2011: 285.

58 Ioh. Bicl., Chron. 27. Su localización sigue siendo una incógnita para la historiografía, aunque hay un cierto consenso en situarla entre las actuales provincias de Salamanca, Zamora y el noreste de Portugal. Sobre esta problemática, véase Díaz, 1997: 267; Martín Viso, 2002: 33; García Moreno, 2008: 57.

59 Martín Viso, 2006: 129. En otras palabras, «they sometimes saw the gentes which no longer existed but which they expected to see». Garipzanov et alii, 2008: 4. Véase también Descola, 1996: 183.

60 Martín Viso, 2006: 129, quien aplica esta idea al caso vascón. No descartamos que tales comunidades hubiesen mostrado un mínimo de cohesión, aunque consideramos que esta, en caso de haberse producido, emergió a raíz de ese contexto de tensión con los visigodos. Véase Descola, 1996: 174.

61 Esta indiferencia ha sido advertida también en Martín Viso, 2002: 32.

62 Isid. Hisp., Hist. 61. Sobre tales colectivos, véase Diego Santos, 1979; Novo Guisán, 1992; Besga Marroquín, 1983; Menéndez Bueyes, 2001.

${ }_{63}$ Algunos historiadores han intuido la importancia del botín en la sociedad visigoda, aunque en ningún momento lo han abordado de manera específica. Véase Martin, 2003: 290-291; Innes, 2007: 222; Moreno Resano, 2011: 308; Sarris, 2011: 189-192. El carácter predatorio de estas campañas contra los pueblos peninsulares encuentra una confirmación en el célebre epígrafe de Opilano, quien murió realizando este tipo de acciones de pillaje. ICERV, 284. Véase Moreno Resano, 2011: 305. Para una valoración historiográfica del botín de guerra en estos contextos, véase Keller, 2018.

64 Véase Carrié, 1995. 
de las mejores y más rápidas maneras de obtener fortuna, constituyendo la principal remuneración que recibían las tropas por sus servicios militares ${ }^{65}$. Esta remuneración a partir del producto obtenido como botín de guerra añadía un plus de motivación a las tropas, puesto que el pago dependía en exclusiva de lo que las tropas fuesen capturando en el transcurso de las expediciones ${ }^{66}$. La propia legislación deja constancia de la importancia del pillaje para la sociedad visigoda desde los tiempos de Eurico ${ }^{67}$, al igual que la obra de Isidoro de Sevilla, quien dedica un apartado de sus Etymologiae a desglosar exhaustivamente las distintas variantes terminológicas de botín y pillaje ${ }^{68}$.

El botín de guerra no tenía únicamente un valor económico, sino también uno simbólico, al constituir la prueba visible del mérito y, por extensión, del prestigio militar de un determinado individuo ${ }^{69}$. Es aquí donde radicaba el valor principal de las riquezas muebles obtenidas durante las acciones de saqueo ${ }^{70}$. Esta rentabilidad de las campañas militares, ya fuera en términos económicos o simbólicos ${ }^{71}$, explica que fuesen los propios señores los que sufragasen el coste del equipamiento militar de sus hombres ${ }^{72}$. Si hubiese regido el interés público sobre el privado, lo más normal habría sido que estos hubiesen exigido al monarca el coste de tales gastos. La monarquía se habría encargado únicamente del abastecimiento en el transcurso de la campaña, siendo aquí donde radicaba la utilidad de la annona militar referida en la legislación ${ }^{73}$. Por otro lado, estas ansias de botín habrían dificultado a los reyes el control de las tropas en el transcurso de las expediciones militares, que se lanzaban al saqueo sin reparar en si se trataban de los territorios del reino o del enemigo. Para responder contra este tipo de acciones, se establecieron una serie de penas para aquellos que sometiesen a pillaje el espacio del regnum ${ }^{74}$; medidas que al mismo tiempo confirman la preocupación de la monarquía por desviar toda la acción militar hacia agentes de alteridad.

La depraedatio se caracterizaba por la destrucción de los cultivos y las casas, la toma de prisioneros de guerra y el robo de ganado ${ }^{75}$, entre otras riquezas muebles no concretadas normalmente en las fuentes ${ }^{76}$. Sin embargo, el bien más cotizado habría sido la tierra, conside-

65 Grierson, 1959; Brown, 2012: 395.

66 De forma complementaria, las tropas recibían en ocasiones las indemnizaciones económicas que debían pagar aquellos que intentasen desertar y aquellos oficiales que lo permitiesen. $L V$, IX, 2,1 .

$67 C E, 323 ; L V$, IV $, 5,5$.

68 Isid. Hisp., Etym. V, 7, 2.

69 Jucker, 2009; Keller, 2013: 23-24.

70 Tal y como afirma Le Jan, 2011: 81, «les richesses acquises par la prédation, par le pillage ou le butin peuvent avoir du fait même de leur mode d'acquisition 'viril et guerrier' une valeur spécifique faire d'eux des objets précieux, au sens anthropologique du terme».

71 No debemos menospreciar la rentabilidad simbólica de la guerra y del botín obtenido en ella, aunque el valor económico de los bienes fuese menor. Véase Halsall, 2018: 66. Tal y como afirma este autor (ibidem: 55-58), aunque el beneficio económico fuese relativo, este venía compensado por el capital simbólico que reportaban tales bienes. Véase también Sarti, 2018: 190.

72 LV, V, 3, 1-2; IX, 2, 9. Moreno Resano, 2011: 313-314 relativiza esta rentabilidad.

73 LV, IX, 2, 6. Sánchez-Albornoz, 1970: 11-12; Pérez Sánchez, 1989: 118.

74 LV, VIII, 1, 6; VIII, 1, 9-11. Isidoro de Sevilla deslegitima este tipo de saqueos en el interior de las fronteras del reino. Isid. Hisp., Etym. X, 219. Véase Keller, 2018: 21. Julián de Toledo pone de manifiesto tales dificultades de control de las tropas. Iul. Tol., Hist. Wamb. 10.

75 Testimoniando la devastación de los territorios atacados, Greg. Tur., DLH, IX, 7; Isid. Hisp., Hist. 59; Iul. Tol., Hist. Wamb. 10. Recogiendo la toma de prisioneros como parte del botín de guerra: Ioh. Bicl., Chron. 35; Greg. Tur., DLH VIII, 30; IX, 7; IX, 31; Isid. Hisp., Hist. 58; 61-62; Iul. Tol., Hist. Wamb. 10-11; 27. Estos prisioneros estarían destinados bien al intercambio por un rescate o por otro prisionero de guerra, o bien a convertirse en esclavos o en esposas en el caso de las mujeres. Véase, Lenski, 2011; Joye, 2010; Sarti, 2018: 182-184. Mencionando el botín en forma de ganado: Greg. Tur., DLH, IX, 7; LV, VIII, 1, 6; Iul. Tol., Hist. Wamb., 27.

76 Greg. Tur., DLH IX, 31. Los bienes preciosos habrían formado parte del botín de guerra. Evidencia de ello la encontramos en Iul. Tol., Hist. Wamb. 11; 26. 
rada parte integrante del botín obtenido ${ }^{77}$. Es aquí donde enmarcamos la conquista territorial, al estar implícita en muchos casos en las acciones de pillaje ${ }^{78}$. Es en este sentido en el que entendemos por qué la expansión territorial visigoda en la Península no se llevó a cabo como un objetivo en sí mismo, sino como una consecuencia colateral derivada de intereses mucho más inmediatos como era la consecución de un sustancioso botín de guerra $\mathrm{y}$, como parte del mismo, de nuevas tierras que pudieran ser redistribuidas entre la aristocracia guerrera del reino. Este es el objetivo que habría subyacido ante todo con la toma de Sevilla por parte de Atanagildo $^{79}$, o del enclave de Assidona (Medina Sidonia) ${ }^{80}$, de Córdoba ${ }^{81}$, de los Montes Aregenses $^{82}$, de la Orosped $a^{83}$ y del reino suevo en tiempos de Leovigildo ${ }^{84}$. Con una idea similar se habrían retomado también las expediciones de conquista sobre las posesiones imperiales a partir del reinado de Sisebuto ${ }^{85}$. A pesar de lo que se suele pensar, es posible que sus aspiraciones hubiesen sido bastante limitadas y que, por tanto, no hubiese perseguido ni mucho menos el dominio completo de la Spania bizantina. Los objetivos minimalistas de Sisebuto, limitados a la obtención de un botín de guerra mixto, en forma de tierras, prisioneros de guerra y otras riquezas muebles ${ }^{86}$, encuentra su confirmación en el viraje que hizo de su política hacia el Imperio y sus enclaves peninsulares. El monarca cesó sus acciones de conquista sobre el sureste peninsular a raíz de unas negociaciones en torno a la liberación de prisioneros de guerra $^{87}$. Todo ello a pesar de que el contexto era propicio para concluir la conquista de la Spania imperial, puesto que los efectivos militares imperiales radicados en la Península en estos momentos no eran numerosos ${ }^{88}$. Más allá de que las fuentes dibujen este viraje político como un acto de la magnanimidad regia o a causa del alto número de víctimas con los que se saldaron los enfrentamientos, lo cierto es que Sisebuto dejó de ver beneficios en estas acciones de conquista sobre el Imperio, concretamente en un momento en el que disfrutaba de cierta

77 Isid. Hisp., Etym. X, 219; XV, 13, 5. Véase Innes, 2006: 64.

78 Un ejemplo de ello lo constituyen las campañas de Leovigildo contra la Sabaria, el senior loci Aspidio y el reino suevo, acciones en las que se alude al saqueo, pero también a la integración del territorio en el regnum Gothorum. Ioh. Bicl., Chron. 27; 32; 35; 72. Se pone también en relación la conquista con la obtención de riquezas en Isid. Hisp., Hist. 49. Tal y como afirma Cosentino, 2018: 211 aplicado al conjunto del Occidente post-romano, «the prevailing model was one that entailed the expropriation of portions of the defeated peoples' landed property by the victors». Véase Bossen, 2006a: $241,253$.

79 Chron. Caesar. 6a.

80 Ioh. Bicl., Chron. 17. En este caso también pudieron subyacer unas motivaciones estratégicas dirigidas a privar a los imperiales de una plaza proclive a ser empleada en momentos puntuales como lanzadera militar contra los visigodos.

81 Ioh. Bicl., Chron. 20. Su toma se justifica a partir de la supuesta actitud rebelde de la ciudad, aunque no tenemos constancia de su integración previa en el regnum. La misma idea es aplicable al conjunto del territorio bético, sobre el cual la influencia visigoda debió de ser mínima y ocasional, al menos hasta los tiempos de Leovigildo. Hasta entonces debió de tratarse de un espacio gobernado por poderes locales autónomos. Así se posicionan también, Hillgarth, 1985: 495; Kulikowski, 2004.

82 Ioh. Bicl., Chron. 35. La localización de los susodichos montes constituye una cuestión lejos de estar resuelta, sin encontrar consenso entre la historiografía. Para una propuesta reciente, véase Díaz, 2011: 189-190.

83 Ioh. Bicl., Chron. 46. Su localización genera no pocos interrogantes, aunque hay consenso en situarla en el cuadrante sudoriental de la península ibérica. Véase Poveda Navarro, 1991: 615; Díaz, 2004: 54-55; García Moreno, 2008: 78; Vallejo Girvés, 2012: 230-231.

84 Ioh. Bicl., Chron. 72; 75; Isid. Hisp., Chron. 407; Hist. 92. En este caso, sin embargo, pudieron subyacer otras razones, de tipo político fundamentalmente, que requieren un estudio individualizado en investigaciones futuras.

85 Isid. Hisp., Chron. 415; Hist. 61; Fredeg., Chron. IV, 33. Wood, 2010: 318. Tales campañas vinieron facilitadas por el traslado paulatino de tropas imperiales al convulso frente oriental. Ibidem: 335 . Es posible que el enclave de Málaga hubiese caído en manos visigodas en estos momentos. Barbero, 1989: 185.

86 La captura de prisioneros en el transcurso de estas campañas encuentra su confirmación en Ep. Wisig. II.

87 Ep. Wisig. II; Isid. Hisp., Hist. 61.

88 Los contingentes bizantinos no debían de superar los 5000 efectivos. Nos basamos en las estimaciones de Vallejo Girvés, 2012: 334; Vizcaíno Sánchez, 2013: 281. 
fortaleza en su posición ${ }^{89}$. Finalmente, Suintila se apropió del resto de enclaves bajo dominio bizantino $^{90}$, quizás por las mismas razones. De todas formas, después del reinado de Sisebuto, pocos habrían sido los enclaves que permanecían bajo dominio imperial ${ }^{11}$.

Las expediciones ofensivas no tenían que ir necesariamente encaminadas a la adquisición de un botín en forma de tierras, sino que estas podían limitarse a la toma de riquezas en forma de bienes muebles o prisioneros de guerra ${ }^{92}$. Este habría sido el caso, por ejemplo, de la desafortunada expedición de Agila contra Córdoba ${ }^{93}$, o las posteriores de Atanagildo contra el mismo enclave ${ }^{94}$. En un sentido similar interpretamos aquellas campañas de Leovigildo que no se saldaron con la toma de nuevos territorios ${ }^{95}$. En el caso de la campaña de Witerico contra Sagontia se dice que esta se saldó únicamente con la toma de prisioneros ${ }^{96}$. Una impresión similar obtenemos del reinado de su sucesor, Gundemaro, de quien se dice que saqueó y devastó el territorio de los vascones y atacó a los imperiales ${ }^{97}$. No se percibe, por tanto, una actitud de conquista del territorio, tampoco en las expediciones militares de Sisebuto y Suintila contra los pueblos del norte ${ }^{98}$. Después de la toma de la Spania bizantina, y hasta la caída del reino, podemos considerar que todas las campañas dirigidas contra estos tuvieron este fin ${ }^{99}$.

Sobre el papel del monarca en la distribución del botín, pocas son las evidencias al respecto, aunque debemos suponer que en un momento dado los reyes se atribuyeron plenas atribuciones redistributivas sobre el mismo, que repartirían entre su comitiva armada directa y entre la aristocracia que le seguía a las expediciones con sus respectivos séquitos ${ }^{100}$. En todo este proceso, los reyes más hábiles se habrían asegurado apropiarse para sí mismos y para el fisco de una parte importante del producto de los pillajes ${ }^{101}$. Por tanto, la instrumentalización regia de la guerra pasaba también por enriquecerse más que el resto en el proceso redistributivo del botín de guerra ${ }^{102}$. Después del monarca, la principal beneficiada en los repartos habría sido la aristocracia militar goda, especialmente en lo que a tierras se refiere ${ }^{103}$, dado que la redistribución del botín se hacía de forma equitativa en función de la condición del receptor y del mérito en el campo de batalla ${ }^{104}$. A esto se le sumarían los derechos sobre el botín de guerra adquirido

\footnotetext{
89 Sobre los mecanismos empleados para su consecución, véase Valverde Castro, 2000: 264-265.

90 Isid. Hisp., Chron. 416b; Hist., 62.

91 Vallejo Girvés, 2012: 334-368.

92 Desde una perspectiva antropológica, véase Cohen, 1984: 336.

93 Isid. Hisp., Hist. 45. Desde la arqueología se ha observado una correlación cronológica entre los proyectos de reforzamiento defensivo de la ciudad con las campañas de Agila. Hidalgo Prieto, 2005: 405-406.

94 Chron. Caesar. 6a.

95 Ioh. Bicl., Chron. 12; 35; 38; 60; Greg. Tur., In Glor. Confess, 12. Aduce una motivación similar para la primera de las campañas: Martin, 2003: 288. Proponiendo distintas propuestas sobre la posible extensión del territorio de Cantabria, Castellanos, 1994: 127; García González, 1995: 183; Martín Viso, 1999: 156; Díaz, 2006; García Moreno, 2008: 64-66.

96 Isid. Hisp., Hist. 58. Rechaza también la toma del enclave por parte visigoda: Velázquez, 2000: 592. Para esta campaña, el monarca aprovechó un contexto de debilidad militar del Imperio en la Península. Véase Vallejo Girvés, 2012: 323.

97 Isid. Hisp., Hist. 59.

98 Isid. Hisp., Hist. 61; 63; Siseb., Epist. Siseb. reg. Goth. Missa ad Isid. de Libr. Rot. 5-8.

99 Estas campañas han sido mencionadas supra.

100 Una de las pocas certezas que podemos extraer de las fuentes es que los bienes entregados como botín de guerra tenían una consideración diferente a aquellos entregados a la aristocracia en forma de regalos. $L V$, IV, 5,5 .

101 Isid. Hisp., Etym. V, 7, 2. Leovigildo constituye, de nuevo, el mejor ejemplo al respecto. Valverde Castro, 2000: 144. Isidoro de Sevilla pone en relación la actividad militar de este monarca con su enriquecimiento personal. Isid. Hisp., Hist. 49; 51. Sobre el enriquecimiento del fisco por la vía militar, Isid. Hisp., Hist. 49. Sobre el enriquecimiento de los gobernantes en un plano general, véase Sarti, 2018: 185.

102 Hardt, 1998: 267; Valverde Castro, 2011: 267.

103 Barbero y Vigil, 1978: 38.

104 Isid. Hisp., Etym. V, 7, 2; XVIII, 2, 8.
} 
por sus siervos y dependientes ${ }^{105}$. Por ello se entiende que habrían sido las élites militares visigodas las más interesadas en que las expediciones ofensivas se sucediesen con mayor regularidad, siendo responsabilidad del monarca de turno promoverlas. De hecho, debemos suponer que cuanto mayor fuera el botín en juego, mayor éxito habría tenido el gobernante de turno en la llamada a armas.

A consecuencia precisamente del interés que revistieron siempre este tipo de acciones, tanto para la monarquía como para la aristocracia, estas se siguieron llevando a cabo con cierta regularidad, también en momentos tardíos. Para estos momentos, concretamente después de la conquista de los últimos enclaves bizantinos, la tierra dejó de formar parte del botín, pero no por ello este dejó de ser ambicionado ${ }^{106}$. A partir de entonces, el objetivo principal de los visigodos fueron los pueblos del norte, los cuales consideramos que no fueron plenamente integrados en el reino visigodo en ningún momento de su historia ${ }^{107}$. Es cierto que las fuentes aluden, por ejemplo, en el caso de Cantabria a una conquista territorial con Leovigildo ${ }^{108}$, pero también lo hacen durante el reinado de Sisebuto ${ }^{109}$. Asimismo, también en tiempos de este último, se aplica el calificativo de rebellantes para etiquetar a algunos de estos pueblos, siendo este el caso de los astures, dando la impresión de que hasta ese momento este pueblo había formado parte integrante del reino desde las campañas de Leovigildo ${ }^{110}$. No rechazamos la imposición visigoda sobre tales gentes, pero no creemos que esta supusiera una plena conquista territorial. No se tiene constancia de cecas permanentes o de una densa red diocesana radicadas en estas zonas como para pensar en una mínima penetración del poder visigodo sobre tales territorios ${ }^{111}$. De hecho, fuentes tardías, como la Historia Wambae, transmiten la idea de que la Cantabria, al menos alguna de sus partes, constituía una parte ajena al reino ${ }^{112}$.

A nuestro parecer, la dominación impuesta sobre los pueblos del norte no habría pasado del mero régimen tributario, más puntual que regular, a la manera que los merovingios impusieron sobre los pueblos situados en su periferia, sin que estos formasen plenamente parte del regnum Francorum $^{113}$. Los visigodos habrían optado especialmente por imponer este régimen como castigo a razzias de estos pueblos, eso sí, siempre después de una campaña de pillaje dirigida desde Toledo ${ }^{114}$. Quizás el caso más elocuente al respecto sea el de los vascones ${ }^{115}$, un pueblo

${ }^{105}$ La legislación establece que la propiedad última del botín obtenido por estos correspondía al señor. $L V$, IV, 2,15 ; $\mathrm{V}, 3,1-2$.

${ }^{106}$ Así lo reflejan: Iul. Tol., Hist. Wamb. 10; 18; 27. El carácter más o menos regular de las expediciones militares de pillaje queda también de manifiesto en otra ley de Recesvinto que regula la transmisión hereditaria de los bienes adquiridos como botín de guerra. $L V$, IV, 2, 16. Este fenómeno no fue exclusivo de la sociedad visigoda, sino que se reprodujo en otros reinos del Occidente altomedieval. Véase Steuer, 2006: 227-236.

107 Defendiendo la ausencia de un control real visigodo del septentrión peninsular, Barbero y Vigil, 2012: 35-48.

${ }^{108}$ Ioh. Bicl., Chron. 32; Braul. Caesar., VSA 26

${ }^{109}$ Fredeg., Chron. IV, 33.

110 Así lo creen, por ejemplo, Novo Guisán, 1992: 71; Ruiz Gutiérrez, 1999: 461-462.

111 Véase, Barbero y Vigil, 2012: 57-59; Poveda Arias, 2017: 87-90.

${ }_{112}$ Iul. Tol., Hist. Wambae, IX, 171-175.

113 Keller, 2013.

114 Ponen en evidencia acciones de rapiña por parte de cántabros y vascones: Isid. Hisp., Etym. IX, 2, 113; Taius, Epist. praef. ad Quiric. Barcinon. ep. 2; Braul. Caesar., Epist., II; Chron. Moz. a. 754, 27. Véase, Barbero y Vigil, 2012: 46; Besga Marroquín, 1983: 53-57. Tales incursiones vasconas habrían sido ante todo acciones independientes de determinados líderes locales y no tanto iniciativas coordinadas entre las distintas comunidades del territorio. De Brestian, 2011: 297. Las expediciones de respuesta habrían servido además como forma de reivindicación de la supremacía militar visigoda sobre estas gentes y, con ello, disuadirlas de emprender futuras razzias. Véase Keegan, 1995.

${ }^{115}$ Este sería el caso de las referidas campañas de Sisebuto y Suintila en el septentrión peninsular. Defendiendo la imposición de un régimen tributario a los vascones, Martín Viso, 2006: 131-133. Es posible que este hubiese sido el mismo régimen al que sometieron a la Sabaria. Martín Viso, 2002: 33-34. 
que sabemos con cierta certeza que nunca se integró plenamente en el reino visigodo ${ }^{116}$. Dicho régimen se renovaría después de nuevos episodios conflictivos y de saqueo entre ambas partes ${ }^{117}$. La consecución de tales tributos habría sido perseguida especialmente por la monarquía, al constituir un medio con el que nutrir sus arcas sin necesidad de una redistribución inmediata de los ingresos, tal y como ocurría con el producto de los saqueos ${ }^{118}$. Pero obviamente los reyes no podían privar a sus tropas, y en concreto a la aristocracia militar del reino, de las oportunidades de obtención de riquezas y prestigio a partir de estas acciones de pillaje. Es posible que, a consecuencia de esta necesidad, los monarcas visigodos hubiesen desistido de controlar de forma efectiva el septentrión peninsular con el fin de no perder las oportunidades de pillaje que les ofrecían las poblaciones allí radicadas y, por tanto, dejando abierta una vía continua para la obtención de botín ${ }^{119}$. Si aceptamos este punto de vista, la unidad del territorio hispano bajo soberanía visigoda habría estado lejos de ser, no ya una pretensión, sino una realidad ${ }^{120}$.

\section{CONCLUSIONES}

A modo de conclusión, tal y como hemos pretendido exponer a lo largo de las páginas anteriores, caben lecturas alternativas a la hora de valorar el proceso expansionista de los visigodos en la península ibérica. Lejos de ver en el mismo la consecución de un proyecto ideológico perseguido por la monarquía visigoda desde tiempos remotos, hemos analizado las distintas campañas ofensivas emprendidas por los godos en Hispania desde el siglo VI como una consecuencia de motivaciones mucho más inmediatas y minimalistas de la monarquía, por un lado, y de la aristocracia guerrera, por otro. De esta manera, los reyes visigodos vieron en la guerra un instrumento con el cual desviar las tensiones internas hacia objetivos externos, cohesionar al grupo armado en torno al líder y, de esta manera, reforzar su posición en un ambiente de constante competición por el poder. Advertimos, por tanto, que los intereses personales de los distintos monarcas desempeñaron un papel de primer orden a la hora de lanzarse a emprender acciones militares de naturaleza ofensiva sobre las distintas regiones de la Península. Sin embargo, en todo este proceso la monarquía no podía obviar los anhelos colectivos, en especial aquellos de la aristocracia, si quería lograr una movilización efectiva de las tropas; unos intereses que podían diferir, pero que podían converger en una misma vía: la guerra. La aristocracia guerrera del reino vería de esta manera en las campañas de naturaleza ofensiva contra agentes de alteridad una vía de obtener un importante beneficio económico y simbólico a través de la obtención de un sustancioso botín de guerra. Este se convertía así en una forma rápida de obtener fortuna, especialmente a través de la toma de nuevas tierras, y prestigio, del cual las riquezas saqueadas constituía su principal exponente. En este esquema, la conquista de nuevos territorios no fue nada más que una consecuencia de esas ansias de botín y gloria por parte de la aristocracia visigoda, pero no constituyó nunca un fin en sí mismo. Observamos por

116 Poniendo en evidencia la entidad autónoma de los vascones en el siglo VI, Ven. Fort., Carm. IX, 1; X, 19. Véase Barbero y Vigil, 2012: 35-36; Martin, 2003: 291; Thompson, 2011: 186. Otra lectura en Besga Marroquín, 1983; Sayas Abengochea, 1988: 70-71; García González, 1995: 185.

117 Así queda de manifiesto en Iul. Tol., Hist. Wambae, 10.

${ }^{118}$ Es aquí donde habría radicado el interés de Leovigildo de no conquistar inicialmente el reino suevo, al que impuso un tributo después de su primera campaña. Ioh. Bicl., Chron. 38.

119 Otro punto de vista en James, 1997. En el caso de su actitud con los vascones, se le sumaría un interés estratégico por mantener una región-tapón entre los francos y el reino visigodo que dificultase posibles razzias merovingias en el regnum Gothorum, al menos por el sector pirenaico noroccidental. Martin, 2003: 290-291.

${ }_{120}$ Tal y como pone de manifiesto Arce, 2009: 40, la pretendida unificación peninsular bajo soberanía visigoda no fue más que una ficción propagandística. 
tanto que, a través de las aportaciones teóricas de la antropología, caben nuevas perspectivas de estudio del proceso formativo del reino visigodo $\mathrm{y}$, en general, de sus dinámicas militares. Especialmente útiles han resultado estas a la hora de vislumbrar el determinismo de los condicionantes sociales en la esfera militar. Sirva al menos este trabajo como acicate para seguir abriendo nuevas vías de investigación en torno al estudio social de las dinámicas militares del Occidente tardoantiguo y altomedieval.

\section{BIBLIOGRAFÍA}

Arce, J. (2009): «The Visigoths in Spain: Old and New Historical Problems», W. Pohl y V. Wieser (eds.), Der frühmittelalterliche Staat - Europäische Perspektiven. Wien, Verlag der Österreichischen Akademie der Wissenschaften: 31-42.

Barbero, A. (1989): «Las divisiones eclesiásticas y las relaciones entre la Iglesia y el Estado en la España de los siglos VI y VII», M. ${ }^{a}$ J. Hidalgo de la Vega (ed.), La historia en el contexto de las ciencias humanas y sociales. Homenaje a Marcelo Vigil Pascual. Salamanca, Ediciones Universidad de Salamanca: 169-190.

Barbero, A. y Vigil, M. (1978): La formación del feudalismo en la Península Ibérica. Barcelona, Crítica.

Barbero, A. y Vigil, M. (2012 [1965]): «Sobre los orígenes sociales de la Reconquista: cántabros y vascones desde fines del Imperio Romano hasta la invasión musulmana», Visigodos, cántabros y vascones en los orígenes sociales de la Reconquista. Pamplona, Urgoiti: 7-72.

Besga Marroquín, A. (1983): Consideraciones sobre la situación política de los pueblos del Norte de España durante la época visigoda del reino de Toledo. Bilbao, Publicaciones de la Universidad de Deusto.

Besga Marroquín, A. (2007): «El “morbo gótico": ¿tópico o realidad?». Letras de Deusto, 37 (117): 135-144.

Bossen, C. (2006a): «Chiefs Made War and War Made State? War and Early State Formation in Ancient Fiji and Hawaii», T. Otto, H. M. Thrane y H. Vandkilde (eds.), Warfare and Society. Archaeological and Social Anthropological Perspectives. Aarhus, Aarhus University Press: 237-259.

Bossen, C. (2006b): «War as Practice, Power, and Processor: A Framework for the Analysis of War and Social Structural Change», T. Otto, H. M. Thrane y H. Vandkilde (eds.), Warfare and Society. Archaeological and Social Anthropological Perspectives. Aarhus, Aarhus University Press: 89-102.

Braul. Caesar., Confess. uel profess. fid. Iudeor. ciuit. = Braulio Caesaraugustanus, Confessio uel professio Iudaeroum civitatis Toletanae. Ed. J. C. Martín-Iglesias (2018): Braulionis Caesaraugustani Epistulae. CC, Series Latina, 114B. Turnhout, Brepols.

Braul. Caesar., Epist. = Braulius Caesaraugustanus, Epistulae. Ed. R. Miguel Franco y J. C. Martín-Iglesias (2018): Braulionis Caesaraugustani Epistulae. CC, Series Latina, 114B. Turnhout, Brepols.

Braul. Caesar., VSA = Braulius Caesaraugustanus, Vita Sancti Aemiliani. Ed. J. Oroz (1978): «Sancti Braulionis Caesaraugustani episcopi. Vita Santi Aemiliani». Perficit, 9 (119-120): 165-228.

Brown, P. (2012): Through the Eye of a Needle. Wealth, the Fall of Rome, and the Making of Christianity in the West. Princeton, Princeton University Press.

Carrié, J.-M. (1995): «L'État à la recherche de nouveaux modes de financement des armées (Rome et Byzance, IVe-VIII ${ }^{\mathrm{e}}$ siècles)», A. Cameron (ed.), The Byzantine and Early Islamic Near East, III. States, Resources and Armies. Princeton, Darwin Press: 27-60.

Castellanos, S. (1994): «Aproximación a la historia política del Alto Valle del Ebro durante los siglos V-VI d. C.». Brocar, 18: 141-150.

Castellanos, S. (2007): Los godos y la cruz: Recaredo y la unidad de 'Spania'. Madrid, Alianza Editorial.

Cazier, P. (1994): Isidore de Séville et la naissance de l'Espagne catholique. Paris, Beauchesne.

$C E=$ Codex Euricianus. Ed. Á. d'Ors (2014 [1960]): El Código de Eurico. Madrid, BOE.

Chron. Caesar.$=$ Chronica Caesaraugustana . Ed. C. Cardelle de Hartmann (2001): Victoris Tvnnvnensis Chronicom cum reliquiis ex consularibus Caesararugustanis et Iohannis Biclarensis Chronicon. CC, Series Latina, 173A. Turnhout, Brepols. 
Chron. Moz. a. 754 = Chronica Mozárabe de 754. Ed. J. E. López Pereira (2009): Continuatio Isidoriana Hispana. Crónica Mozárabe de 754. León, Archivo Histórico Diocesano.

Cohen, R. (1984): «Warfare and State Formation: Wars Make States and States Make Wars», B. Ferguson (ed.), Warfare, Culture, and Environment. New York, Academic Press: 329-358.

Collins, R. (1984): «The Basques in Aquitaine and Navarre: Problems of Frontier Government», J. Gillingham y J. C. Holt (eds.), War and Government in the Middle Ages. Essays in Honour of J. O. Prestwich. Suffolk, The Boydell Press: 3-17.

Concilios visigóticos e hispano-romanos. Ed. J. Vives (1963). Barcelona-Madrid, CSIC.

Cosentino, S. (2018): «Public Power, Military Service and the Early Middle Ages: East and West», A. Kolia-Dermitzaki, V. Seirinidou y S. G. Ploumidis (eds.), Histories of War in South-Eastern Europe. An Approach in the longue durée. Athena, National and Kapodistrian University of AthensHêrodotos Publications: 209-225.

De Brestian, S. C. (2011): «Vascones and Visigoths: Creation and Transformation of Identity in Northern Spain in Late Antiquity», R. W. Mathisen y D. Shanzer (eds.), Romans, Barbarians, and the Transformation of the Roman World: Cultural Interaction and the Creation of Identity in Late Antiquity. Farnham, Ashgate: 283-298.

Descola, P. (1996): «Les affinités sélectives. Alliance, guerre et prédation dans l'ensemble jivaro». L'Homme, 33 (126): 171-190. https://doi.org/10.3406/hom.1993.369635

Díaz, P. C. (1997): «Gallaecia: de reino suevo a provincia visigoda», G. Pereira-Menaut (coord.), Galicia fai dous mil anos: o feito diferencial galego, I, Historia. Santiago de Compostela, A Editorial da Historia: 253-278.

Díaz, P. C. (2004): «En tierra de nadie: visigodos frente a bizantinos. Reflexiones sobre la frontera», I. Pérez Martín y P. Bádenas de la Peña (eds.), Bizancio y la Península Ibérica. De la Antigüedad Tardía a la Edad Moderna. Madrid, CSIC: 37-60.

Díaz, P. C. (2006): «La cristianización de Cantabria antes del Beato», P. Á. Fernández Vega (coord.), Apocalipsis. El ciclo histórico del Beato de Liébana. Santander, Consejería de Cultura, Turismo y Deporte: 45-69.

Díaz, P. C. (2010): «El siglo VI en Galia e Hispania a través de las fuentes escritas». Zona Arqueológica, 11: 349-363.

Díaz, P. C. (2011): El reino suevo (411-585). Tres Cantos, Akal.

Díaz, P. C. (2012): «La dinámica del poder y la defensa del territorio: para una comprensión del fin del reino visigodo de Toledo», De Mahoma a Carlomagno. Los primeros tiempos (siglos VII-IX). Pamplona, Gobierno de Navarra: 167-206.

Diego Santos, F. (1979): «De la Asturias sueva y visigoda». Asturiensia Medievalia, 3: 17-73.

Diesner, H. J. (1978): «Bandas de criminales, bandidos y usurpadores en la España visigoda». Hispania Antiqua, 8: 129-142.

Ep. Wisig. = Epistulae Wisigothicae. Ed. J. Gil (1991 [1972]): Miscellanea Wisigothica. Sevilla, Universidad de Sevilla: 1-49.

Ferguson, R. B. (2008): «Ten Points on War». Social Analysis, 52 (2): 32-49. https://doi.org/10.3167/ sa.2008.520203

Fernández, D. (2017): Aristocrats and Statehood in Western Iberia, 300-600 C.E. Philadelphia, University of Pennsylvania Press.

Fernández Delgado, A.; Martínez Jiménez, J. y Tejerizo García, C. (2013): «Old and New Elites in the Visigothic Kingdom (AD 550-650)», E. M. Van der Wilt y J. Martínez Jiménez (eds.), Though Times: The Archaeology of Crisis and Recovery. Oxford, BAR: 161-170.

Fredeg., Chron. $=$ Fredegarius, Chronicon. Ed. B. Krusch (1888): Fredegarii et aliroum chronica. Vita Sanctorum. MGH, Scriptores Rerum Merouingicarum, T. II. Hannover, Impensis Bibliopolii Hahniani.

Frighetto, R. (2018): «Cuando la confrontación genera la colaboración: godos, romanos y el surgimiento del reino hispanogodo de Toledo (siglos V-VI)». Vinculos de Historia, 7: 157-172.

García González, J. J. (1995): «Incorporación de la Cantabria romana al estado visigodo». Cuadernos burgaleses de historia medieval, 2: 167-230.

García Moreno, L. A. (2008): Leovigildo. Unidad y diversidad de su reinado. Madrid, Real Academia de la Historia. 
Garipzanov, I. H.; Geary, P. J. y Urbanczyk, P. (2008): «Introduction: Gentes, Gentile Identity, and State Formation in Early Medieval Europe», I. H. Garipzanov, P. J. Geary y P. Urbanczyk (eds.), Franks, Northmen and Slavs: Identities and State Formation in Early Medieval Europe. Turnhout, Brepols: 1-14.

Gibert, R. (1956): «El reino visigodo y el particularismo español», I Goti in Occidente. Spoleto, CISAM: 537-584.

Giddens, A. (1984): The Constitution of Society. Outline of the Theory of Structuration. Cambridge, Polity Press.

Greg. Magn., Reg. Epist. = Gregorius Magnus, Registrum Epistolarum. Ed. N. Norberg (1982): S. Gregorii Magni. Registrum Epistularum, Libri VIII-XIV, Appendix. Turnhout, Brepols.

Greg. Tur., DLH = Gregorius Turonensis, Decem Libri Historiae. Ed. B. Krusch y W. Levison (1951): Gregorii Episcopi Turonensis Historiarum Libri X. MGH, Scriptores Rerum Merouingicarum, T. I, P. I. Hannover, Impensis Bibliopolii Hahniani.

Greg. Tur., In Glor. Confess. = Gregorius Turonensis, In Gloria Confessorum. Ed. B. Krusch (1885): Gregorii episcopi Turonensis miracula et opera minora. MGH, Scriptores Rerum Merouingicarum, T. I, P. II. Hannover, Impensis Bibliopolii Hahniani.

Grierson, P. (1959): «Commerce in the Dark Ages: A Critique of the Evidence». Transactions of the Royal Historical Society, Fifth Series, 8: 123-140.

Halsall, G. (2003): Warfare and Society in the Barbarian West, 450-900. London, Routledge.

Halsall, G. (2018): «Predatory Warfare - the Moral and the Physical», R. Keller y L. Sarti (eds.), Pillages, tirbuts, captifs. Prédation et sociétés de l'Antiquité tardive au haut Moyen Âge. Paris, Éditions de la Sorbonne: 53-68.

Hardt, M. (1998): «Royal Treasures and Representation in the Early Middle Ages», W. Pohl y H. Reimitz (eds.), Strategies of Distinction. The Construction of Ethnic Communities, 300-800. Leiden, Brill: 255-280.

Heather, P. (1998): The Goths. Malden, Blackwell Publishers.

Hidalgo Prieto, R. (2005): «Algunas cuestiones sobre la Corduba de la Antigüedad tardía», J. M. ${ }^{\text {a }}$ Gurt y A. Ribera (eds.), VI Reunió d'Arqueologia cristiana hispánica. Les ciutats tardoantigues d'Hispania: cristianització I topografía. Barcelona, Institut d'Estudis Catalans: 401-414.

Hillgarth, J. N. (1970): «Historiography in Visigothic Spain», La storiografia altomedievali. Spoleto, CISAM: 261-311.

Hillgarth, J. N. (1985): «Coins and Chronicles: Propaganda in Sixth-Century Spain and the Byzantine Background», Visigothic Spain, Byzantium and the Irish. London, Variorum Reprints: 483-508.

ICERV = Inscripciones cristianas de la España romana y visigoda. Ed. J. Vives (1942). Barcelona, CSIC.

Innes, M. (2006): «Land, Freedom and the Making of the Medieval West». Transactions of the Royal Historical Society, 16: 39-74. https://doi.org/10.1017/s0080440106000430

Innes, M. (2007): Introduction to Early Medieval Western Europe, 300-900. London - New York, Routledge.

Ioh. Bicl., Chron. = Iohannes Biclarensis, Chronicon. Ed. C. Cardelle de Hartmann (2001): Victoris Tvnnvnensis Chronicom cum reliquiis ex consularibus Caesararugustanis et Iohannis Biclarensis Chronicon. CC, Series Latina, 173A. Turnhout, Brepols.

Isid. Hisp., Chron. = Isidorus Hispalensis, Chronica. Ed. J. C. Martín (2003): Isidori Hispalensis Chronica. CC, Series Latina, 112. Turnhout, Brepols.

Isid. Hisp., Etym. = Isidorus Hispalensis, Etymologiae. Ed. J. Oroz Reta y M.-A. Marcos Casquero (2009): San Isidoro de Sevilla. Etimologías. Edición bilingüe. Madrid, Biblioteca de Autores Cristianos.

Isid. Hisp., Hist. = Isidorus Hispalensis, Historiae. Ed. C. Rodríguez Alonso (1975): Las Historias de los godos, vándalos y suevos de Isidoro de Sevilla. León, Archivo Histórico Diocesano.

Isla, A. (2010): Ejército, sociedad y política en la península ibérica entre los siglos VII y XI. Madrid, Ministerio de Defensa - CSIC.

Iul. Tol., Hist. Wamb. = Iulianus Toletanus, Historia Wambae. Ed. W. Levison (1976): Sancti Iuliani Toletanae sedis episcopi, opera, pars I. CC, Series Latina, 115. Turnhout, Brepols. 
Iul. Tol., Progn. Fut. saec. lib. tres = Iulianus Toletanus, Prognosticon futuri saeculi libri tres. Ed. W. Levison (1976): Sancti Iuliani Toletanae sedis episcopi, opera, pars I. CC, Series Latina, 115. Turnhout, Brepols.

James, E. (1997): «The Militarisation of Roman Society, 400-700», A. N. Jorgensen y B. L. Clausen (eds.), Military Aspects of Scandinavian Society in a European Perspective, AD 1-1300. København, Copenhagen National Museum: 19-24.

Joye, S. (2010): «Le femme comme butin de guerre à la fin de l'Antiquité et au début du Moyen Âge», M. Trevisi y P. Nivet (eds.), Les femmes et la guerre de l'Antiquité à 1918. Paris, Institut d'Stratégie Comparée: 91-108.

Jucker, M. (2009): «Le butin de guerre au Moyen Âge. Aspects symboliques et économiques». Francia, 36: $113-133$.

Keegan, J. (1995 [1993]): Historia de la guerra. Barcelona, Planeta.

Keller, R. (2013): Les profits de la guerre: Prédation et Pouvoir dans le monde franc (VI ${ }^{e} X^{e}$ siècle). Paris, Université de Paris Est [Tesis doctoral inédita].

Keller, R. (2018): «Prédations et sociétés de l'Antiquité tardive au Moyen Âge: remarques introductives», R. Keller y L. Sarti (eds.), Pillages, tributs, captifs. Prédation et sociétés de l'Antiquité tardive au haut Moyen Âge. Paris, Éditions de la Sorbonne: 7-25.

King, P. D. (1981 [1972]): Derecho y sociedad en el reino visigodo. Madrid, Alianza Editorial.

Kulikowski, M. (2004): Late Roman Spain and Its Cities. Baltimore - London, The John Hopkins University Press.

Kulikowski, M. (2005): «Cities and Government in Late Antique Hispania», M. Kulikowski (ed.), Hispania in Late Antiquity. Current Perspectives. Leiden, Brill: 31-75.

Le Jan, R. (2011): «Les élites au haut Moyen Âge : approche sociologique et anthropologique», F. Bougard, H.-W. Goetz y R. Le Jan (eds.), Théorie et pratiques des élites au haut Moyen Âge. Cocneption, perception et réalisation-Theorie und Praxis frühmittelalterlicher Eliten. Konzepte, Wahrnehmung und soziale Umsetzung. Turnhout, Brepols: 69-100.

Lécrivain, C. (1890): «Études sur le Bas-Empire». Mélanges de l’École Française de Rome, 10: 253 283.

Lenski, N. (2011): «Captivity and Roman-Barbarian Interchange», R. W. Mathisen, D. Shanzer (eds.), Romans, Barbarians, and the Transformation of the Roman World. Cultural Interaction and the Creation of Identity in Late Antiquity, Farnham, Ashgate: 185-198.

$L V=$ Lex Visigothorum. Ed. K. Zeumer (1902): Leges Nationum Germanicarum. MGH, Legum Sectio I, T. 1. Hannover, Impensis Bibliopolii Hahniani.

Martin, C. (2003): La géographie du pouvoir dans l'Espagne visigothique. Villeneuve d'Ascq, Presses Universitaires du Septentrion.

Martín Viso, I. (1999): «Organización episcopal y poder en la Antigüedad Tardía y el Medievo (siglos V-XI): las sedes de Calahorra, Oca y Osma». Iberia, 2: 151-190.

Martín Viso, I. (2002): Fragmentos del Leviatán: la articulación política del espacio zamorano en la Alta Edad Media. Zamora, Instituto de Estudios Zamoranos Florián de Ocampo.

Martín Viso, I. (2006): «La configuración de un espacio de frontera: propuestas sobre la Vasconia tardoantigua», U. Espinosa y S. Castellanos (eds.), Comunidades locales y dinámicas de poder en el norte de la Península Ibérica durante la Antigüedad Tardía. Logroño, Universidad de la Rioja: 101-139.

Martínez Pizarro, J. (2005): The Story of Wamba: Julian of Toledo's Historia Wambae regis. Washington DC, The Catholic University of America Press.

Menéndez Bueyes, L. R. (2001): Reflexiones críticas sobre el origen del reino de Asturias. Salamanca, Ediciones Universidad de Salamanca.

Moore, M. E. (2011): A Sacred Kingdom: Bishops and the Rise of Frankish Kingship, 300-850. Washington DC, Catholic University of America Press.

Moreno Resano, E. (2011): «La representación épica del combate y de la muerte del guerrero en el epitafio de Opilano (año 642)». Habis, 42: 299-316.

Moreno Resano, E. (2015): «Vascones, francos y visigodos en los siglos VI y VII: dinámicas de delimitación y división del solar vascón». Príncipe de Viana, 76 (261): 347-357.

Novo Guisán, J. M. (1992): Los pueblos vasco-cantábricos y galaicos en la Antigüedad Tardía. Siglos III-IX. Alcalá de Henares, Servicio de Publicaciones de la Universidad de Alcalá. 
Osborne, J. M. (2018-2019): «A Call to Arms: Cross-Regional Communication and the Visigothic Military». Visigothic Symposium, 3: 55-71.

Otterbein, K. (2009): The Anthropology of War. Long Grove, Waveland Press.

Parra Romo, Á. (2018): «El ejército visigodo en campaña, Wamba y la secesión de la Narbonense». Studia Historica. Historia Antigua, 36: 221-251.

Pérez Sánchez, D. (1989): El ejército en la sociedad visigoda. Salamanca, Ediciones Universidad de Salamanca.

Petersen, L. I. R. (2013): Siege Warfare and Military Organization in the Successor States (400-800): Byzantium, the West and Islam. Leiden, Brill.

Poveda Arias, P. (2017): «A vueltas con la frontera tardoantigua: la Submeseta norte en los confines del reino visigodo». Arkeogazte, 7: 79-96.

Poveda Arias, P. (en prensa): «The Role of the Military Factor in the Political and Administrative Shaping of the Visigothic Kingdom $\left(6^{\text {th }}-7^{\text {th }}\right.$ Centuries $) »$, G. M. Berndt, E. Bennett, S. Esders y L. Sarti (eds.), Early Medieval Militarisation. Manchester, Manchester University Press.

Poveda Navarro, A. M. (1991): «La creación de la sede de Elo en la expansión toledana de finales del s. VI en el S. E. Hispánico», III Concilio, XIV Centenario, 589-1989. Toledo, Arzobispado de Toledo: 611-626.

Procop., $B G=$ Procopius Caesariensis, De Bello Gothico. Ed. H. B. Dewing (1919): Procopius, III, History of the Wars, Books V and VI. Londo-New York, William Heinemann-G.P. Putnams Sons.

Reinhart, W. (1944-1945): «El rey Leovigildo, unificador nacional». Boletín del Seminario de Estudios de Arte y Arqueología, 11: 97-107.

Reuter, T. (1997): «The Recruitment of Armies in the Early Middle Ages: What Can We Know?», A. N. Jorgensen y B. L. Clausen (eds.), Military Aspects of Scandinavian Society in an European Perspective, AD 1-1300. København, Copenhagen National Museum: 32-37.

Reydellet, M. (1981): La royauté dans la littérature latine de Sidoine Apollinaire à Isidore de Séville. Roma, École Française de Rome.

Ruchesi, F. (2016): «El ejército y la Guerra en la construcción de la cohesión. El caso de los visigodos: siglo V y comienzos del VI». Temas Medievales, 24: 161-184.

Ruchesi, F. (2018-2019): «Military Matters in the Visigothic Kingdom: Initial Considerations». Visigothic Symposium, 3: 72-87.

Ruiz Gutiérrez, A. (1999): «Notas sobre la dominación visigoda en Cantabria», J. González (ed.), El mundo mediterráneo (siglos III-VII). Madrid, Ediciones Clásicas: 452-462.

Rus Rufino, S. (2015): «Unidad y paz en el reino visigodo. Dos aspectos del pensamiento político de Isidoro de Sevilla». Antiquité tardive, 23: 81-94. https://doi.org/10.1484/j.at.5.109370

Sahlins, M. (1963): «Poor Man, Rich Man, Big-Man, Chief: Political Types in Melanesia and Polynesia». Comparative Studies in Society and History, 5 (3): 285-303. https://doi.org/10.1017/ s0010417500001729

Sánchez-Albornoz, C. (1970): «El ejército visigodo: su protofeudalización», Investigaciones y documentos sobre las instituciones hispanas. Santiago, Editorial Jurídica de Chile: 5-56.

Sanz, R. (1986): «Aproximación al estudio de los ejércitos privados en Hispania durante la antigüedad tardía». Gerión, 4: 225-264.

Sarris, P. (2011): Empires of Faith. The Fall of Rome to the Rise of Islam, 500-700. Oxford, Oxford University Press.

Sayas Abengochea, J. J. (1988): «La búsqueda visigoda de la unidad territorial y el caso vascónico». Veleia, 5: 189-206.

Sarti, L. (2018): «Methoden, Bedeutung und Legitimation der Aneignung von fremdem Eigentum von der Spätantike zum frühen Mittelalter - Zusammenfassung und Diskussion», R. Keller y L. Sarti (eds.), Pillages, tirbuts, captifs. Prédation et sociétés de l'Antiquité tardive au haut Moyen Âge. Paris, Éditions de la Sorbonne: 179-193.

Sid. Apoll., Epist. = Sidonius Apollinaris, Epistulae. Ed. A. Loyen (1970): Sidoine Apollinaire, Tome II, Lettres (Livres I-V) / Tome III, Lettres (livres VI-VII). Paris, Belles Lettres.

Siseb. Epist. Siseb. reg. Goth. Missa ad Isid. de Libr. Rot = Sisebutus, Epistula Sisebuti regis Gothorum missa ad Isidorum de Libro Rotarum. Ed. J. Fontaine (2002): Isidore de Séville, Traité de la nature. Introduction, texte critique, traduction et notes. Paris, Institut d'Études Augustiniennes. 
Smith, A. D. (1981): «War and Ethnicity: The Role of Warfare in the Formation, Self-Images and Cohesion of Ethnic Communities». Ethnic and Racial Studies, 4 (4): 375-397. https://doi.org/10.1080/0 1419870.1981.9993347

Steuer, H. (2006): «Warrior Bands, War Lords, and the Birth of Tribes and States in the First Millennium AD in Middle Europe», T. Otto, H. M. Thrane y H. Vandkilde (eds.), Warfare and Society. Archaeological and Social Anthropological Perspectives. Aarhus, Aarhus University Press: 227-236.

Taius, Epistula praefatoria ad Quiricum Barcinonensem ep. Ed. M. Risco (1776): España Sagrada, Tomo 31. Madrid, D. Antonio de Sancha.

Teillet, S. (2011 [1984]): Des Goths à la nation gothique. Les origines de l'idée de nation en Occident $d u V^{e}$ au VII ${ }^{e}$ siècle. Paris, Les Belles Lettres.

Theuws, F. C. W. J. (1990): «Centre and Periphery in Northern Austrasia ( $6^{\text {th }}-8^{\text {th }}$ Centuries). An Archaeological Perspective», J. C. Besteman, J. M. Bos y H. A. Heiding (eds.), Medieval Archaeology in the Netherlands. Studies Prestented to H. H. van Regteren Altena, Maastricht, Van Gorcum: 41-69.

Thompson, E. A. (2011 [1969]): Los godos en España. Madrid, Alianza Editorial.

Vallejo Girvés, M. (1996): «The Treaties between Justinian and Athanagild and the Legality of the Byzantine Possession on the Iberian Peninsula». Byzantion, 66: 208-218.

Vallejo Girvés, M. (2012): Hispania y Bizancio. Una relación desconocida. Tres Cantos, Akal.

Valverde Castro, M. ${ }^{a}$ R. (2000): Ideología, simbolismo y ejercicio del poder real en la monarquía visigoda: un proceso de cambio. Salamanca, Ediciones Universidad de Salamanca.

Valverde Castro, M. ${ }^{a}$ R. (2011): «La ideología fiscal en el reino visigodo de Toledo», P. C. Díaz e I. Martín Viso (eds.), Entre el impuesto y la renta. Problemas de fiscalidad tardoantigua y altomedieval. Bari, Edipuglia: 163-188.

Van Dam, R. (2005): «Merovingian Gaul and the Frankish Conquests», P. Fouracre (ed.), The New Cambridge Medieval History, Volume 1: c. 500-700. Cambridge, Cambridge University Press: 193-231.

Velázquez, I. (2000): «Zonas y problemas eclesiásticos durante la época de la presencia bizantina en Hispania (una reflexión sobre los textos)», J. M. Gurt y N. Tena (eds.), V Reunió d'Arqueologia cristiana hispánica - V Reunión de Arqueología cristiana hispánica. Barcelona, Institut d'Estudis Catalans: 585-599.

Ven. Fort., Carm. = Venantius Fortunatus, Carminae. Ed. M. Roberts (2017): Poems, Venantius Fortunatus. Cambridge, MA-London, Harvard University Press.

Vit. Fruct. = Vita Fructuosi. Ed. M. Díaz y Díaz (1974): La Vida de San Fructuoso de Braga. Estudio y edición crítica. Braga, [s. n.].

Vizcaíno Sánchez, J. (2009): La presencia bizantina en Hispania (siglos VI-VII): la documentación arqueológica. Murcia, Universidad de Murcia, Servicio de Publicaciones.

Vizcaíno Sánchez, J. (2013): «Hispania y Oriente durante el período de ocupación bizantina (siglos VI-VII). La documentación arqueológica», M. ${ }^{a}$ P. de Hoz y G. Mora (eds.), El oriente griego en la península ibérica: epigrafía e historia. Madrid, Real Academia de la Historia: 281-305.

Wickham, C. (2009 [2005]): Una historia nueva de la Alta Edad Media: Europa y el mundo mediterráneo, 400-800. Barcelona, Crítica.

Wolf, K. B. (1999): Conqueros and Chroniclers of Early Medieval Spain. Liverpool, Liverpool University Press.

Wood, I. (2006): «Royal Succession and Legitimation in the Roman West, 416-536», S. Airlie, W. Pohl y H. Reimitz (eds.), Staat im frühen Mittelalter. Wien, Verlag Der Österreichischen Akademie der Wissenschaften: 59-72.

Wood, J. (2010): «Defending Byzantine Spain: Frontiers and Diplomacy». Early Medieval Europe, 18 (3): 292-319. https://doi.org/10.1111/j.1471-8847.2010.00300.x

Wood, J. (2012): The Politics of Identity in Visigothic Spain: Religion and Power in the Histories of Isidore of Seville. Leiden - Boston, Brill.

Recibido: 02-12-2019

Aceptado: 15-03-2020 